\title{
Elevated blood pressure among primary school children in Dar es salaam, Tanzania: prevalence and risk factors
}

\author{
Alfa J. Muhihi ${ }^{1 *}$, Marina A. Njelekela ${ }^{2}$, Rose N. M. Mpembeni ${ }^{3}$, Bikolimana G. Muhihi ${ }^{4}$, Amani Anaeli ${ }^{5}$, Omary Chillo², \\ Sulende Kubhoja ${ }^{6}$, Benjamin Lujani ${ }^{2}$, Mwanamkuu Maghembe $^{2}$ and Davis Ngarashi ${ }^{2}$
}

\begin{abstract}
Background: Whilst the burden of non-communicable diseases is increasing in developing countries, little data is available on blood pressure among Tanzanian children. This study aimed at determining the blood pressure profiles and risk factors associated with elevated blood pressure among primary school children in Dar es Salaam, Tanzania.

Methods: We conducted a cross sectional survey among 446 children aged 6-17 years from 9 randomly selected primary schools in Dar es Salaam. We measured blood pressure using a standardized digital blood pressure measuring machine (Omron Digital HEM-907, Tokyo, Japan). We used an average of the three blood pressure readings for analysis. Elevated blood pressure was defined as average systolic or diastolic blood pressure $\geq 90$ th percentile for age, gender and height.

Results: The proportion of children with elevated blood pressure was 15.2\% (pre-hypertension 4.4\% and hypertension 10.8\%). No significant gender differences were observed in the prevalence of elevated BP. Increasing age and overweight/obese children were significantly associated with elevated BP ( $p=0.0029$ and $p<0.0001)$ respectively. Similar associations were observed for age and overweight/obesity with hypertension. $(p=0.0506$ and $p<0.0001$ ) respectively. In multivariate analysis, age above 10 years (adjusted $\mathrm{RR}=3.63,95 \% \mathrm{Cl}=1.03-7.82$ ) was significantly and independently associated with elevated BP in this population of school age children.

Conclusions: We observed a higher proportion of elevated BP in this population of school age children. Older age and overweight/obesity were associated with elevated BP. Assessment of BP and BMI should be incorporated in school health program in Tanzania to identify those at risk so that appropriate interventions can be instituted before development of associated complications.
\end{abstract}

Keywords: Prevalence, Elevated blood pressure, Age, Overweight, Obesity, Children, Tanzania

\section{Background}

Elevated blood pressure (BP) in childhood has increasingly become a public health problem of global concern [1]. The prevalence of hypertension in children and adolescents in developing countries has been established through systematic reviews to be between 1 and 5\% [2,3]. In developing countries, particularly African countries, there is a wide variation in the estimated prevalence of hypertension in children and adolescent population

\footnotetext{
* Correspondence: selukundo@gmail.com

${ }^{1}$ Management and Development for Health, Mikocheni, Dar es Salaam, Tanzania

Full list of author information is available at the end of the article
}

ranging from $<5 \%$ to as high as $>20 \%$ [4-6]. Elevated BP tends to develop during the first two decades of life [7] and may persist through adult life [8]. Risk factors for elevated BP during childhood include age, gender, body size, socioeconomic status, obesity, family history of hypertension, changes in dietary habits, sedentary lifestyle and increasing stress [9-11].

Several studies have demonstrated increasing mean $\mathrm{BP}$ with increasing age in children [12, 13]. Obesity is the main determinant of $\mathrm{BP}$ in children and adolescents $[14,15]$. Blood pressure studies in children provide crucial epidemiological information helpful in the modification of risk factors for coronary heart diseases and 
other non-communicable diseases later in life [16]. Several studies have consistently reported that elevated BP is significantly correlated with body mass index [17-19]. Identification and modification of risk factors may reduce the incidence and complications associated with elevated BP later in adult life. The 1996 task force report on BP in children recommended that BP measurements be incorporated into routine pediatric examination for children aged 3 years and above [20]. However, such recommendations are rarely followed, mainly because hypertension in the pediatric population is not appreciated and given emphasis like in adults. Despite the greater potential for success rate of lifestyle modification interventions in children as opposed to adults, most prevention and control strategies for hypertension target adult population [21]. Interventions targeting children should be a higher priority for prevention of hypertension and other lifestyle related non-communicable diseases.

The prevalence of hypertension among Tanzania children and adolescents remains largely unknown despite evidence of increasing childhood obesity [22]. It is imperative to understand the prevalence and risk factors for elevated BP in children and adolescents in Tanzania, since there is a greater variability in the reported prevalence from other African countries. Understanding the magnitude and factors for elevated BP in Tanzanian children and adolescents will help in the planning and implementation of appropriate prevention strategies. This study was therefore conducted to estimate the proportion of elevated BP and its associated risk factors among primary school age children in Dar es Salaam, Tanzania.

\section{Methods}

\section{Study design and participants}

We conducted this cross-sectional survey among primary school children aged 6-17 years from 9 randomly selected primary schools in in Dar es Salaam region. Dar es Salaam is the most populated city in Tanzania, with little known information about elevated blood pressure especially among primary school age children. We used a cross-sectional design so as to capture the required multiple data from the selected study population at one point in time.

\section{Sample size and sampling technique}

We determined sample size for the study using EPI INFOR6 STAT CALC based on the following assumptions; expected prevalence of $6 \%$ estimated from previous study [23]; significance level $95 \%$ and a desired precision of $2 \%$. Of the eligible 542, informed consent and assent was obtained for a total of 466, thus providing a response rate of $86 \%$.
A sampling frame comprised of all primary schools, both public and private obtained from the municipal educational officers of Ilala, Kinondoni and Temeke in Dar es Salaam. We selected schools randomly so as to ensure equal representation of schools from both rural and urban settings. For each school, we randomly selected one class out of seven classes (class I - class VII) and all children and their parents/ guardian from the selected class were invited to participate into the study. Children with disability or suffering from a serious illness that could impair anthropometric and blood pressure measurements were excluded from the study.

\section{Data collection procedures}

Data collection methods have been described elsewhere [22, 24, 25]. Briefly, data collection was conducted by trained research assistants using data collections tools comprising of both closed and open-ended questions. Research assistants provided information about the aims, nature, study procedures and measurements to parents and/or guardians of the selected children. A written informed consent was then obtained for parents/guardians who agreed their children to participate in the study. Data collected included; age, date of birth, gender, type of school (public/private), grade, height, weight, blood pressure (systolic and diastolic), number of adults and children in the family, maternal education and occupation, and amount of pocket money given to the child to spend at school. All research assistants wore regular clothing during the entire data collection process, anthropometric and blood pressure measurements.

\section{Anthropometric measurements}

Anthropometric measurements were conducted by trained research assistants early in the morning before starting classes. Anthropometric measurements were conducted in specially prepared room at each school. Children were weighed wearing light clothes and with no shoes. Body weight was measured to the nearest $0.1 \mathrm{~kg}$ using a self-calibrating precision digital scale (Omron, Japan) and height to the nearest $0.1 \mathrm{~cm}$ using a fixed Shorr measuring board (Shorr Productions, Olner, MD). Body weight and height were then converted to metric measurements for calculation of Body Mass Index (BMI) as weight $(\mathrm{kg})$ divided by square of height $\left(\mathrm{m}^{2}\right)$. All measurements were taken while observing standard precautions [26]. Obesity in this population of primary school children was defined based on BMI percentiles for age and gender. Children with BMI at or above 95th percentile for age and gender were considered obese [27]. 


\section{Blood pressure measurements and definition of elevated} blood pressure

We measured blood pressure using a standardized digital blood pressure measuring machine (Omron Digital HEM-907, Tokyo, Japan). We took three blood pressure readings following at least 5-10 min of rest. Blood pressure was measured on the left upper arm and in a seated position using age appropriate child blood pressure cuffs. We used an average of the three blood pressure readings during analysis. We calculated SBP and DBP percentiles according to age, gender and height in accordance with the 4th report on diagnosis, evaluation and treatment of hypertension in children and adolescents [28]. Blood pressure status was classified according to SBP and/or DBP percentiles as follows;

a) Normal blood pressure: Average SBP and/or average DBP $<90$ th percentile

b) Pre-hypertension: Average SBP and/or average DBP $\geq 90$ th percentile but $<95$ th percentile

c) Hypertension: Average SBP and/or average DBP $\geq 95$ th percentile

In this study, we defined elevated blood pressure as average SBP and/or average $\mathrm{DBP} \geq 90$ th percentile for age, gender and height (combination of pre-hypertension and hypertension).

\section{Statistical analysis}

Data analysis ranged from descriptive statistics (means, standard deviations and frequencies) to identification of important associations. The proportion of elevated BP (average SBP and/or average $\mathrm{DBP} \geq 90$ th percentile) and that of hypertension (average SBP and/or average DBP $\geq$ 95th percentile) were computed. Log-binomial regression models were used to generate relative risk estimates to assess factors associated with elevated BP. Factors assessed in univariate and multivariate analyses included child age ( $\leq 10$ years and $>10$ years), gender (boys and girls), body mass index (underweight, normal weight, overweight and obese), place of residence (rural and urban), number of adults in the family ( $<6$ people and $\geq 6$ people), number of children in the family ( $<3$ children and $\geq 3$ children) and amount of pocket money given to spend at school $(\leq 500$ and > 500 Tanzanian shillings). The $95 \%$ confidence intervals were calculated for both unadjusted and adjusted relative risks. All statistical analyses were performed using Statistical Analysis Software (SAS 9.2, Institute Inc., North Carolina, USA). All the significant tests were 2-sided at a $p$-value $\leq 0.05$.

\section{Results}

Descriptive characteristics of children who participated in the study are summarized in Table 1 . The mean age
Table 1 Socio-demographic and anthropometric characteristics of primary school children in Dar es Salaam, Tanzania

\begin{tabular}{ll}
\hline Characteristic & Mean \pm SD or N (\%) \\
\hline Age (years) & $11.1 \pm 2.0$ \\
Age category & \\
$\quad \leq 10$ years & $138(30.9)$ \\
$>10$ years & $308(69.1)$ \\
Gender & \\
Boys & $209(46.9)$ \\
Girls & $237(53.1)$
\end{tabular}

Place of residence

$\begin{array}{ll}\text { Rural } & 197(44.2)\end{array}$

Urban $249(55.8)$

Body mass $(\mathrm{kg}) \quad 34.1 \pm 11.8$

Height $(\mathrm{cm}) \quad 142.1 \pm 13.3$

BMI $\left(\mathrm{kg} / \mathrm{m}^{2}\right) \quad 16.6 \pm 4.0$

BMI-defined categories

Underweight 65 (14.6)

Normal $314(70.4)$

Overweight $\quad 44(9.8)$

Obese $23(5.2)$

SBP $(\mathrm{mmHg}) \quad 103.9 \pm 10.3$

DBP $(\mathrm{mmHg}) \quad 65.6 \pm 8.2$

Blood pressure categories

Normal BP $376(84.3)$

Pre-hypertension $22(4.9)$

Stage 1 hypertension 39 (8.8)

Stage 2 hypertension $9(2.0)$

Elevated blood pressure

$\begin{array}{ll}\text { Yes } & 68(15.2)\end{array}$

No $398(84.8)$

Hypertension

Yes $48(10.8)$

No 378 (89.2)

Number of adults in the family ( $\geq 18$ years)

Less than 6 adults $187(41.9)$

6 and above adults $\quad 259(58.1)$

Number of children in the family ( $<18$ years)

Less than 3 children 201 (45.1)

3 and above children 245 (54.9)

Pocket money to spend at school

$\leq 500$ Tanzanian shillings $\quad 315(70.6)$

> 500 Tanzanian shillings $\quad 131$ (29.4)

$B M I$ Body Mass Index, DBP Diastolic Blood Pressure, SBP Systolic Blood Pressure, SD Standard Deviation 
was $11.1 \pm 2.0$ years. Of the 446 primary school age children included in this analysis, 237 (53.1\%) were girls and 249 (55.8\%) were residing in urban settings of Dar es Salaam. The mean BMI was $16.6 \pm 4.0 \mathrm{~kg} / \mathrm{m}^{2}$, and proportion of overweight and obesity were $9.8 \%$ and $5.2 \%$ respectively. Body mass index was significantly higher among girls $(p=0.012)$.

Overall, the proportion of children with elevated BP was $15.2 \%$ (Pre-hypertension at $4.4 \%$ and hypertension at $10.8 \%)$. No statistically significant differences were observed in the proportion of elevated BP between boys and girls in this population. Figure 1 summarizes the proportion of elevated BP by BMI categories. Proportion of elevated BP was higher for overweight (27.3\%) and obese children (52.2\%) compared to $12.3 \%$ and $12.1 \%$ among underweight and normal weight children. A similar trend was observed for hypertension with $20.4 \%$ and $47.8 \%$ of overweight and obese children being hypertensive (results not shown).

The associations between elevated BP and other characteristics of the children are shown in Table 2. Children with elevated BP had significantly higher mean values for age, weight, height and BMI (all $p<0.001$ ). The mean BMI was $2.7 \mathrm{~kg} / \mathrm{m}^{2}$ higher for children with elevated $\mathrm{BP}$ compared to their counterparts with normal BP. Similarly, prevalence of overweight and obesity was $23 \%$ (34.4\% vs $11.4 \%)$ higher among children with elevated $\mathrm{BP}$ compared to those with normal BP. As for age, prevalence of elevated BP was higher among children aged more than 10 years compared to those aged 10 years or less $(p=0.0029)$. Children residing in urban settings of Dar es Salaam had statistically insignificant higher prevalence of elevated BP compared to those from rural settings.

Unadjusted and adjusted analysis of risk factors for elevated BP is presented in Table 3. Children above
10 years of age had a 3.6 times higher risk for elevated BP compared to their counter parts aged 10 year or less [adjusted $\mathrm{RR}=3.63$ (95\% CI: 1.03-7.82), $p=0.0450$ ]. Although not statistically significant, overweight and obese children had increased risk for elevated BP compared to normal weight children [adjusted $\mathrm{RR}=1.82$ $(0.21-5.73)$ ] and [adjusted $R R=2.21(0.12-3.67)$. Having 3 or more children was protective against elevated BP with a borderline significance in univariate analysis, but this protective effect disappeared when other factors were taken into consideration in the multivariate analysis.

\section{Discussion}

The current study presents the findings of blood pressure profile among primary school age children from rural and urban settings of Dar es Salaam, in Tanzania. Our findings demonstrate a higher proportion of elevated BP of $15.2 \%$ and that of hypertension (stage I and stage II) of $10.8 \%$ in this surveyed population of primary school children. Blood pressure increased with age in both boys and girls.

Our finding of elevated BP are comparable to other studies conducted in Tanzania [23, 29]. However, there are some differences in the definition of hypertension worth noting. Contrast to our study which considered hypertension as having either systolic and/ or diastolic hypertension as per the fourth report on the diagnosis, evaluation and treatment of high blood pressure in children and adolescents [28], both studies by Chillo et al. and Mushengezi et al. [23, 29] reported the prevalence of isolated SBP and DBP and that of combined. Our study therefore provides a good estimate of the prevalence of both prehypertension and hypertension in this population of school age children in Dar es Salaam.

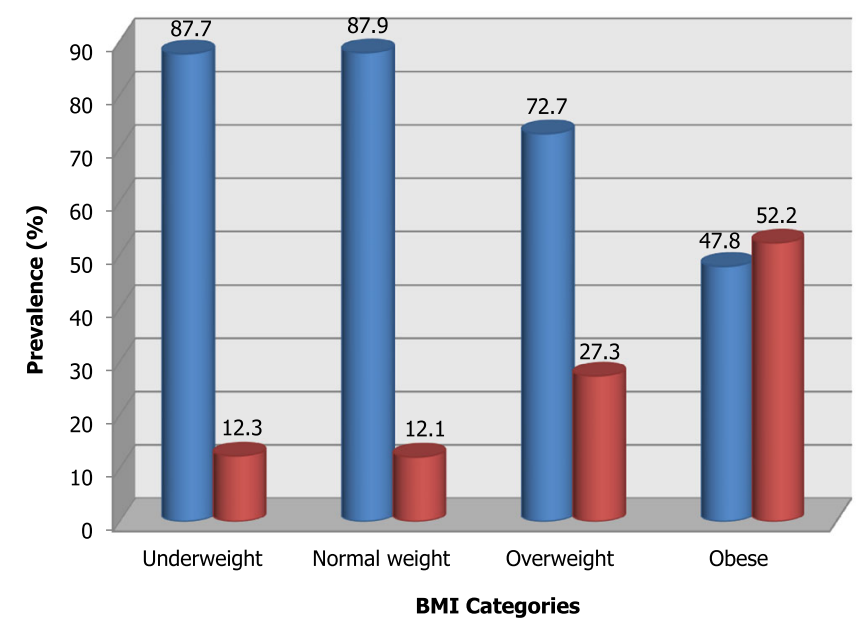

$\square$ Normal BP

$\square$ Elevated BP

Fig. 1 Prevalence of elevated BP and hypertension by BMI category among school age children in Dar es Salaam 
Table 2 Socio-demographic and anthropometric characteristics of children with elevated blood pressure in Dar es Salaam, Tanzania

\begin{tabular}{|c|c|c|c|c|}
\hline & All & Normal BP & Elevated BP & $p$-value \\
\hline & Mean \pm SD N (\%) & Mean \pm SD N (\%) & Mean \pm SD N (\%) & \\
\hline Age (years) & $11.1 \pm 2.0$ & $11.1 \pm 2.1$ & $12.1 \pm 1.8$ & 0.0001 \\
\hline \multicolumn{5}{|l|}{ Age category } \\
\hline$\leq 10$ years & $138(30.9)$ & $127(33.8)$ & $11(15.7)$ & \multirow[t]{2}{*}{0.0029} \\
\hline$>10$ years & $308(69.1)$ & $249(66.2)$ & $59(84.3)$ & \\
\hline \multicolumn{5}{|l|}{ Gender } \\
\hline Boys & 209 (46.9) & $174(46.3)$ & $35(50.0)$ & \multirow[t]{2}{*}{0.5665} \\
\hline Girls & $237(53.1)$ & $202(53.7)$ & $35(50.0)$ & \\
\hline Body mass (kg) & $34.1 \pm 11.8$ & $32.5 \pm 10.7$ & $42.8 \pm 13.7$ & $<0.0001$ \\
\hline Height (cm) & $142.1 \pm 13.3$ & $140.6 \pm 12.8$ & $149.8 \pm 13.6$ & $<0.0001$ \\
\hline BMI (kg/m2) & $16.6 \pm 4.0$ & $16.1 \pm 3.6$ & $18.9 \pm 5.2$ & $<0.0001$ \\
\hline \multicolumn{5}{|l|}{ BMI category } \\
\hline Underweight & $65(14.6)$ & $57(15.2)$ & $8(11.4)$ & \\
\hline Normal weight & $314(70.4)$ & $276(73.4)$ & $38(54.2)$ & \multirow[t]{3}{*}{$<0.0001$} \\
\hline Overweight & $44(9.8)$ & $32(8.5)$ & $12(17.2)$ & \\
\hline Obese & $23(5.2)$ & $11(2.9)$ & $12(17.2)$ & \\
\hline \multicolumn{5}{|l|}{ Place of residence } \\
\hline Rural & $197(44.2)$ & $169(44.9)$ & $28(40.0)$ & \multirow[t]{2}{*}{0.4441} \\
\hline Urban & $249(55.8)$ & $207(55.1)$ & $42(60.0)$ & \\
\hline \multicolumn{5}{|l|}{ Number of adults in family } \\
\hline Less than 6 adults & 187 (41.9) & $157(41.8)$ & $30(42.9)$ & \multirow[t]{2}{*}{0.8638} \\
\hline 6 and above adults & $259(58.1)$ & $219(58.2)$ & $40(57.1)$ & \\
\hline \multicolumn{5}{|l|}{ Number of children } \\
\hline Less than 3 children & $201(45.3)$ & $163(43.4)$ & $38(54.3)$ & \multirow[t]{2}{*}{0.0914} \\
\hline 3 and above children & $245(54.7)$ & $223(56.6)$ & $22(45.7)$ & \\
\hline \multicolumn{5}{|l|}{ Pocket money for school } \\
\hline$\leq 500$ Tanzanian shillings & $315(70.5)$ & $268(71.3)$ & $47(67.1)$ & \multirow[t]{2}{*}{0.4857} \\
\hline > 500 Tanzanian shillings & $131(29.5)$ & $108(28.7)$ & $23(32.9)$ & \\
\hline
\end{tabular}

BMI Body Mass Index, BP Blood Pressure, DBP Diastolic Blood Pressure, SBP Systolic Blood Pressure, SD Standard Deviation

The prevalence of elevated BP among children is showing a declining trend in some countries like United States [30] Seychelles [31] and Japan [32], however, other countries such as United Kingdom [33] and Peoples Republic of China [34] have reported increasing trend. Studies conducted elsewhere in Africa among children and adolescents have also reported elevated blood pressure levels $[35,36]$. The proportion of children with elevated BP reported in our study is also alarming and factors associated with the increase need to be explored and addressed urgently.

We did not observe statistically significant association between overweight/obesity with elevated BP. However, overweight and obese children had 1.8 and 2.2 times higher risk for elevated BP respectively compared to normal weight children. Studies conducted elsewhere in Africa have reported association of overweight/obesity with elevated BP. A study conducted among urban South African children aged 6 to 13 years found higher BP among children with higher BMI [37]. Similar relationship between BMI and BP has also been reported in Ghana and Cameroon studies [5, 38].

Our findings of higher prevalence of elevated blood pressure in older children concur with other studies conducted in Africa [39-41]. Age-related increase in blood pressure is partly attributable to increasing weight with age. The correlation between BP and BMI in children highlights the development of metabolic syndrome, a relationship that has already been established [42]. However, our findings contrast with those reported by Chiolero et al. [31], who found higher prevalence of elevated BP among younger children. Their possible explanation for such findings were a reaction alert (white coat hypertension) among younger than older children 
Table 3 Relationship between age, gender, body mass index and sociodemographic factors with prevalence of hypertension among primary school children in Dar es Salaam, Tanzania

\begin{tabular}{|c|c|c|c|c|}
\hline Variable & $\begin{array}{l}\text { Unadjusted RR } \\
(95 \% \mathrm{Cl})\end{array}$ & $P$ value & $\begin{array}{l}\text { Adjusted RR } \\
(95 \% \mathrm{Cl})\end{array}$ & $P$ value \\
\hline \multicolumn{5}{|l|}{ Age } \\
\hline$\leq 10$ years & Ref & & Ref & \\
\hline$>10$ years & $5.46(1.60-8.62)$ & 0.0067 & $3.63(1.03-7.82)$ & 0.0450 \\
\hline \multicolumn{5}{|l|}{ Gender } \\
\hline Girls & Ref & & Ref & \\
\hline Boys & $1.08(0.70-1.67)$ & 0.7318 & $1.07(0.70-1.61)$ & 0.7604 \\
\hline \multicolumn{5}{|l|}{ BMI $\left(\mathrm{kg} / \mathrm{m}^{2}\right)$} \\
\hline Underweight & $1.07(0.52-2.19)$ & & $1.22(0.59-2.51)$ & \\
\hline Normal & Ref & & Ref & \\
\hline Overweight & $1.21(0.14-6.46)$ & 0.8602 & $1.82(0.21-5.73)$ & 0.5885 \\
\hline Obese & $1.29(0.07-2.87)$ & & $2.21(0.12-3.67)$ & \\
\hline \multicolumn{5}{|l|}{ Place of residence } \\
\hline Rural & Ref & & Ref & \\
\hline Urban & $1.44(0.59-3.53)$ & 0.4250 & $0.99(0.37-2.61)$ & 0.9795 \\
\hline \multicolumn{5}{|l|}{ Number of adults in family } \\
\hline Less than 6 adults & Ref & & Ref & \\
\hline 6 and above adults & $0.94(0.39-2.28)$ & 0.8909 & $1.13(0.47-2.74)$ & 0.7817 \\
\hline \multicolumn{5}{|l|}{ Number of children } \\
\hline Less than 3 children & Ref & & Ref & \\
\hline 3 and above children & $0.43(0.18-1.03)$ & 0.0581 & $0.47(0.19-1.18)$ & 0.1076 \\
\hline \multicolumn{5}{|l|}{ Pocket money for school } \\
\hline$\leq 500$ Tanzanian shillings & Ref & & Ref & \\
\hline > 500 Tanzanian shillings & $1.49(0.59-3.73)$ & 0.3936 & $0.98(0.39-2.47)$ & 0.9673 \\
\hline
\end{tabular}

RR Risk Ratio, BMI Body Mass Index, Cl Confidence interval

${ }^{\mathrm{a}}$ Risk ratio adjusted for age, gender, place of residence, BMI, number of adults and children in the family, pocket money and BMI category

and a measurement bias due to use of automated blood pressure device (larger versus smaller arms). Although we also used automated blood pressure measuring devices in our study, we used age appropriate blood pressure cuff size to help minimize measurement bias.

Our findings of lack of gender difference in the prevalence of elevated blood pressure concur with reports by Chillo et al. and Mushengezi et al. [23, 29]. Male gender is however a well known risk factor for elevated BP in children and adolescents [43]. Sex steroids have been strongly implicated in explaining the differences in risk of high blood pressure [44]. Lifestyle related behavior such as sedentary lifestyle / physical inactivity could account for the gender differences in the prevalence of elevated BP in children. Studies on physical activity have indicated gender differences in the level of physical activity and that boys are likely to be more physically active than girls [45]. Physical activity may have a blood pressure-lowering effect through increased capillary formation [46]. However, this study did not assess physical activity in the studied population of school age children and cannot draw any conclusions on the association between physical activity and prevalence of elevated BP.

Our analysis has several limitations. The sampled children may not represent the children in Dar es Salaam or Tanzania. Therefore, the generalizability of these finding to the greater Tanzanian children must be done with caution. Although we took three blood pressure measurements, 5-10 min apart, they were all taken on one occasion, contrary to the recommendations [28], that blood pressure measurements be taken on three different occasions or using ambulatory blood pressure monitoring. This method may lead to elevated blood pressure in this population being overestimated due to white coat hypertension in children. It has been shown that prevalence of elevated blood pressure may be decreased by about half on repeated blood pressure measurements [47]. Due to short time of the study and funding limitations, we did not assess many several other factors such as birth weight, dietary information, physical inactivity and genetic factors that may have affected our findings. 


\section{Conclusion}

High blood pressure during childhood and adolescent period is a strong risk factor for development of cardiovascular diseases later in adulthood [48, 49]. Based on the methodology we used, the proportion of children with elevated BP was 15.2\% (4.4 pre-hypertension and $10.8 \%$ hypertension. Without undermining the need for conducting other studies in children and adolescent population that will BP measurements on different occasions or ambulatory $\mathrm{BP}$ monitoring, to better estimate the magnitude of hypertension, the findings this study highlight the need for immediate interventions in primary schools including incorporation of assessment of BP and BMI in school health programs in Tanzania. Such school health programs would enable identification of children with elevated BP and BMI at an early stage for appropriate interventions to be instituted, hence prevent development of serious health complication during childhood and later in adult life. Further studies should also assess and fully explore factors associated with elevated BP in children in resource limited settings like Tanzania.

\section{Abbreviations}

BMI: Body mass index; BP: Blood pressure; DBP: Diastolic blood pressure; RR: Relative risk; SAS: Statistical analysis software; SBP: Systolic blood pressure

\section{Acknowledgements}

We thank the parents who consented for their children to participate and the children themselves who participated in this study. We thank the district education officers for their support. Special thanks to the heads of schools and teachers where the study was conducted for their unlimited support.

\section{Funding}

This study received funding support from Muhimbili University of Health and Allied Sciences (MUHAS). The funder had no influence on data collection, data analysis, or writing of the manuscript.

\section{Availability of data and materials}

The datasets used and/or analyzed during the current study are available from the corresponding author on reasonable request.

\section{Authors' contributions}

AJM analyzed and interpreted the data, drafted and revised the manuscript. MAN conceived and designed the study, participated in data collection and critically reviewed the manuscript. RNM analyzed data and critically reviewed the manuscript. BGM participated in the interpretation of findings and writing of the manuscript. AA OC SK MM and DN participated in data collection and reviewed the manuscript. BL took anthropometric measurements and reviewed the manuscript. All authors read and approved the final manuscript version for publication.

\section{Ethics approval and consent to participate}

The study received ethical approval from the Research Ethics Review Committee of Muhimbili University of Health and Allied Sciences. A written informed consent to participate into the study was obtained from the parents/guardians of the selected children prior to the study. Children provide assent to participate.

\section{Consent for publication}

Not applicable

\section{Competing interests}

The authors declare that they have no competing interest.

\section{Publisher's Note}

Springer Nature remains neutral with regard to jurisdictional claims in published maps and institutional affiliations.

\section{Author details}

${ }^{1}$ Management and Development for Health, Mikocheni, Dar es Salaam, Tanzania. ${ }^{2}$ Department of Physiology, Muhimbili University of Health and Allied Sciences, Dar es Salaam, Tanzania. ${ }^{3}$ Department of Epidemiology and Biostatistics, Muhimbili University of Health and Allied Sciences, Dar es Salaam, Tanzania. ${ }^{4}$ Department of Community and Rural Development, Moshi Cooperative University, Kilimanjaro, Tanzania. ${ }^{5}$ Department of Development Studies, Muhimbili University of Health and Allied Sciences, Dar es Salaam, Tanzania. 'Department of Pediatrics and Child Health, Muhimbili University of Health and Allied Sciences, Dar es Salaam, Tanzania.

Received: 19 June 2016 Accepted: 6 February 2018

Published online: 13 February 2018

\section{References}

1. Kearney PM, Whelton M, Reynolds K, Whelton PK, He J. Worldwide prevalence of hypertension: a systematic review. J Hypertens. 2004;22(1): $11-9$.

2. Redwine KM, Acosta AA, Poffenbarger T, Portman RJ, Samuels J. Development of hypertension in adolescents with pre-hypertension. J Pediatr. 2012;160(1):98-103.

3. Kollias A, Dafni M, Poulidakis E, Ntineri A, Stergiou GS. Out-of-office blood pressure and target organ damage in children and adolescents: a systematic review and meta-analysis. J Hypertens. 2014;32(14):2315-31.

4. Ejike CE, Ugwu CE, Ezeanyika LU, Olayemi AT. Blood pressure patterns in relation to geographic area of residence: a cross-sectional study of adolescents in Kogi state, Nigeria. BMC Public Health. 2008;8:411.

5. Agyemang C, Redekop WK, Owusu-Dabo E, Bruijnzeels MA. Blood pressure patterns in rural, semi-urban and urban children in the Ashanti region of Ghana, West Africa. BMC Public Health. 2005;5:114

6. Woelk G, Emanuel I, Weiss NS, Psaty BM. Birthweight and blood pressure among children in Harare, Zimbabwe. Arch Dis Child Fetal Neonatal Ed. 1998;79(2):F119-22.

7. Chadha S. R T, Shekhawat S, Gopinath N. An epidemiological study of blood pressure in school children (5-14 years) in Delhi. Indian hear. J. 1999;51(2): 178-82.

8. Labarthe DR. Prevention of cardiovascular risk factors in the first place. Prev Med (Baltim). 1999;29(6 Pt 2):S72-8.

9. Sorof J, Daniels S. Obesity hypertension in children: a problem of epidemic proportions. Hypertension. 2002;40(4):441-7.

10. Falkner B. Hypertension in children and adolescents: epidemiology and natural history. Pediatr Nephrol. 2010;25(7):1219-24.

11. Rodríguez-Moran M, Aradillas-García C, Simental-Mendia LE, MonrealEscalante E, de la Cruz ME, Dávila Esqueda ME, et al. Family history of hypertension and cardiovascular risk factors in prepubertal children. Am J Hypertens. 2010;23(3):299-304.

12. Lande MB, Flynn JT. Treatment of hypertension in children and adolescents. Pediatr Nephrol. 2009;24:1939-49.

13. Din-Dzietham R, Liu Y, Bielo MV, Shamsa F. High blood pressure trends in children and adolescents in national surveys, 1963 to 2002. Circulation. 2007;116(13):1488-96.

14. Urrutia-Rojas X, Egbuchunam CU, Bae S, Menchaca J, Bayona M, Rivers PA, et al. High blood pressure in school children: prevalence and risk factors. BMC Pediatr. 2006;6:32

15. Goldring D, Hernandez A, Choi S, Lee JY, Londe S, Lindgren FT, et al. Blood pressure in a high school population. II. Clinical profile of the juvenile hypertensive. J. Pediatr. 1979;95(2):298-304.

16. Veena KG. Prevalence of hypertension in the paediatric population in coastal South India. Australas Med J. 2010;3(11):695-8.

17. Turconi G, Maccarini L, Bazzano R, Roggi C. Overweight and blood pressure: results from the examination of a selected group of adolescents in northern Italy. Public Heal Nutr. 2008;11(9):905-13.

18. Silva KS, Silva RCR, Duarte MFS, Lopes AS, Silva FM. Undernutrition and obesity associated with high blood pressure in children and adolescents from João Pessoa, Paraíba, Brazil. Pediatr Cardiol. 2009:30(3): 248-55. 
19. Kumar J, Deshmukh PR, Garg BS. Prevalence and correlates of sustained hypertension in adolescents of rural Wardha, central India. Indian J Pediatr. 2012;79(9):1206-12.

20. National High Blood Pressure Education Program Working Group on Hypertension Control in Children and Adolescents. Update on the 1987 task force report on high blood pressure in children and adolescents: a working group report from the National High Blood Pressure Education Program. Pediatrics. 1996;98(4 Pt 1):649-58.

21. Chobanian AV, Bakris GL, Black HR, Cushman WC, Green LA, Izzo JL, et al. The seventh report of the joint National Committee on prevention, detection, evaluation, and treatment of high blood pressure: the JNC 7 report. JAMA. 2003;289(19):2560-72.

22. Muhihi AJ, Mpembeni RN, M a N, Anaeli A, Chillo O, Kubhoja S, et al. Prevalence and determinants of obesity among primary school children in Dar es Salaam, Tanzania. Arch. Public Health. Archives of Public Health. 2013;71(1):26.

23. Chillo P, Lwakatare J, Janabi M, Matuja W, Greve G. Low prevalence of cardiovascular disease risk factors among primary school children in Tanzania: an opportunity for primordial prevention? Tanzania Med J. 2009; 24(2):9-14.

24. Mpembeni RNM, Muhihi AJ, Muhihi AJ, Maghembe M, Ngarashi D, Lujani B, et al. Overweight, obesity and perceptions about body weight among primary schoolchildren in dar es salaam, Tanzania. Tanzan J Health Res. 2014;16(4):304-11.

25. Njelekela MA, Muhihi A, Mpembeni RNM, Anaeli A, Chillo O, Kubhoja S, et al. Knowledge and attitudes towards obesity among primary school children in Dar es salaam, Tanzania. Niger Med J. 2015;56(2):103-8.

26. Cogill B. Anthropometric indicators measurement guide. Washington, DC food and nutrition technical assistance (FANTA) project, FHI 360; 2003.

27. Cole T, Bellizzi M, Flegal K, Dietz W. Establishing a standard definition for child overweight and obesity worldwide: international survey. BMJ. 2000; 320(7244):1240-3.

28. Program NHBPE. The fourth report on the diagnosis, evaluation, and treatment of high blood pressure in children and adolescents. Pediatrics. 2004;114(2 Suppl 4th report):555-76.

29. Mushengezi B, Chillo P. Association between body fat composition and blood pressure level among secondary school adolescents in Dar es Salaam, Tanzania. Pan Afr Med J 2014;19:327.

30. Xi B, Zhang T, Zhang M, Liu F, Zong X, Zhao M, et al. Trends in elevated blood pressure among US children and adolescents: 1999-2012. Am J Hypertens. 2016;29(2):217-25.

31. Chiolero A, Madeleine G, Gabriel A, Burnier M, Paccaud F, Bovet P. Prevalence of elevated blood pressure and association with overweight in children of a rapidly developing country. J Hum Hypertens. 2007; 21(2):120-7.

32. Shirasawa T, Ochiai H, Nishimura R, Morimoto A, Shimada A, Ohtsu T, et al. Secular trends in blood pressure among Japanese schoolchildren: a population-based annual survey from 1994 to 2010. J Epidemiol. 2012;22(5): 248-53.

33. Peters H, Whincup P, Cook D, Law C, Li L. Trends in blood pressure in 9 to 11-year-old children in the United Kingdom 1980-2008: the impact of obesity. J Hypertens. 2012;30(9):1708-17.

34. Dong B, Wang H-J, Wang Z, Liu J-S, Ma J. Trends in blood pressure and body mass index among Chinese children and adolescents from 2005 to 2010. Am J Hypertens. 2013:26(8):997-1004.

35. Oduwole AO, Ladapo TA, Fajolu IB, Ekure EN, Adeniyi OF. Obesity and elevated blood pressure among adolescents in Lagos, Nigeria: a crosssectional study. BMC Public Health. 2012;12:616.

36. Aounallah-Skhiri H, El Ati J, Traissac P, Ben Romdhane H, Eymard-Duvernay $\mathrm{S}$, Delpeuch $\mathrm{F}$, et al. Blood pressure and associated factors in a north African adolescent population. A national cross-sectional study in Tunisia. BMC Public Health. 2012;12:98.

37. Monyeki KD, Kemper HCG, Makgae PJ. The association of fat patterning with blood pressure in rural south African children: the Ellisras longitudinal growth and health study. Int J Epidemiol. 2006;35(1):114-20.

38. Proctor MH, Moore LL, Singer MR, Hood MY, Nguyen USDT, Ellison RC. Risk profiles for non-communicable diseases in rural and urban schoolchildren in the Republic of Cameroon. Ethn Dis. 1996;6(3-4):235-43.

39. Umar A, Mustafa A, Muuta I. Prevalence of elevated blood pressure among primary school children in Kano metropolis, Nigeria. Nig J Cardiol. 2016; 13(1):57-61
40. Abolfotouh MA, Sallam SA, Mohammed MS, Loutfy AA, Hasab AA. Prevalence of elevated blood pressure and association with obesity in egyptian school adolescents. Int J Hypertens. 2011;2011:952537.

41. Goon D, Amusa L, Mhlongo D, Khoza L, Any-Anwu F. Elevated blood pressure among rural south African children in Thohoyandou, South Africa. Iran J Public Health. 2013;42(5):489-96.

42. Hu Y-H, Reilly KH, Liang Y-J, Xi B, Liu J-T, Xu D-J, et al. Increase in body mass index, waist circumference and waist-to-height ratio is associated with high blood pressure in children and adolescents in China. J Int Med Res. 2011; 39(1):23-32.

43. Riley M, Bluhm B. High blood pressure in children and adolescents. Am Fam Physician. 2012;85(7):693-700.

44. Ojeda NB, Intapad S, Alexander BT. Sex differences in the developmental programming of hypertension. Acta Physiol. 2014;210(4):307-16.

45. Tucker $P$. The physical activity levels of preschool-aged children: a systematic review. Early Child Res Q. 2008;23(4):547-58.

46. Wallberg-Henriksson H, Gunnarsson R, Henriksson J. Influence of physical training on formation of muscle capillaries in type I diabetes. Diabetes. 1984;33(9):851-7.

47. Sorof JM, Lai D, Turner J, Poffenbarger T, Portman RJ. Overweight, ethnicity, and the prevalence of hypertension in school-aged children. Pediatrics. 2004:113(3 Pt 1):475-82.

48. Miersch A, Vogel M, Gausche R, Siekmeyer W, Pfäffle R, Dittrich K, et al. Blood pressure tracking in children and adolescents. Pediatr Nephrol. 2013; 28(12):2351-9.

49. Lane D. A, gill P. Ethnicity and tracking blood pressure in children. J Hum Hypertens. 2004;18(4):223-8.

\section{Submit your next manuscript to BioMed Central and we will help you at every step:}

- We accept pre-submission inquiries

- Our selector tool helps you to find the most relevant journal

- We provide round the clock customer support

- Convenient online submission

- Thorough peer review

- Inclusion in PubMed and all major indexing services

- Maximum visibility for your research

Submit your manuscript at www.biomedcentral.com/submit
) Biomed Central 